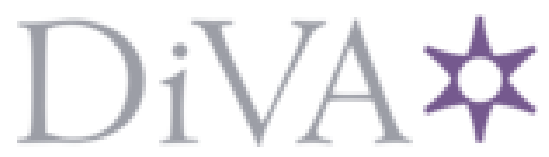

http://www.diva-portal.org

This is the published version of a paper published in Physical Education and Sport Pedagogy.

Citation for the original published paper (version of record):

Barker, D., Quennerstedt, M., Annerstedt, C. (2015)

Inter-student interactions and student learning in health and physical education: a post-

Vygotskian analysis.

Physical Education and Sport Pedagogy, 20(4): 409-426

http://dx.doi.org/10.1080/17408989.2013.868875

Access to the published version may require subscription.

N.B. When citing this work, cite the original published paper.

Permanent link to this version:

http://urn.kb.se/resolve?urn=urn:nbn:se:oru:diva-32851 


\section{Inter-student interactions and student learning in health and physical education: a post-Vygotskian analysis}

\section{Barker, M. Quennerstedt \& C. Annerstedt}

To cite this article: D. Barker, M. Quennerstedt \& C. Annerstedt (2015) Inter-student interactions and student learning in health and physical education: a post-Vygotskian analysis, Physical Education and Sport Pedagogy, 20:4, 409-426, DOI: 10.1080/17408989.2013.868875

To link to this article: http://dx.doi.org/10.1080/17408989.2013.868875

$$
\begin{aligned}
& \text { (c) } 2013 \text { The Author(s). Published by Taylor \& } \\
& \text { Francis }
\end{aligned}
$$

\section{曲 Published online: 17 Dec 2013.}

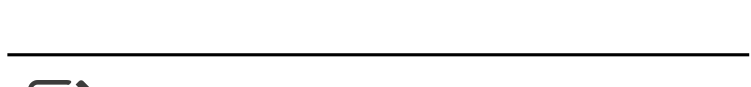

Submit your article to this journal $[\pi$

\section{Џll Article views: 3518}

\section{Q View related articles $\sqsubset$}

View Crossmark data $\asymp$

Citing articles: 7 View citing articles $₫$ 


\title{
Inter-student interactions and student learning in health and physical education: a post-Vygotskian analysis
}

\author{
D. Barker ${ }^{\mathrm{a} *}$, M. Quennerstedt ${ }^{\mathrm{b}}$ and C. Annerstedt ${ }^{\mathrm{a}}$ \\ ${ }^{a}$ Department of Food and Nutrition, and Sport Science, University of Gothenburg, Gothenburg, \\ Sweden; ${ }^{b}$ School of Health and Medical Sciences, Örebro University, Örebro, Sweden
}

(Received 25 January 2013; final version received 20 November 2013)

Background: Group work is often used in Physical Education (and Health - HPE). In this paper, we propose that despite: (1) its widespread use; (2) advances surrounding HPE models that utilize group strategies; and (3) a significant amount of literature dealing with group work in other school subjects, we do not have a particularly good theoretical understanding of group learning in HPE.

Purpose: The purpose of this paper is to propose one way of conceptualizing individual learning in peer interaction based on three tenets of post-Vygotskian theory that relate to the zone of proximal development (ZPD); namely that in learning situations: (i) group members engage in shared communication; (ii) expert-novice relationships can develop and change during group activities and (iii) constructing knowledge can be thought of as reaching agreement.

Participants and setting: Empirical material was generated with eight different HPE classes in lower and upper secondary schools in Sweden. Schools were selected in a way that maximized variation and were distributed across four geographic locations with varying sizes and types of communities.

Data collection: Observational material was produced at each of the sites with the use of two cameras: one stationary and the other mobile. Stationary filming maintained a wideangled focus and captured the entire class. Mobile filming focused on different groups working within the classes. During mobile filming, between two and five students were generally in the frame and filming was directed at sequences in which a group of students worked together on a specific task.

Data analysis: Analysis of the data focused on two kinds of incidents. The first comprised a sequence in which two or more students were interacting to complete a task which they could not immediately do and were engaged in collective signification by talking about or doing the activity in mutually compatible ways. These conditions were sufficient in our view to signal the creation of a ZPD. The second kind of incident fulfilled the first criteria but not the second - i.e. the students were interacting but not in mutually compatible ways.

Findings: A post-Vygotskian interpretation of three group work sequences draws attention to: (i) the flexible and fluid nature of 'expertness' as it exists within groups; (ii) the unpredictable nature of member interactions and (iii) the challenging role that teachers occupy while trying to facilitate group work.

Conclusion: Such an interpretation contributes to a growing understanding of group work and helps HPE practitioners to make the most of a teaching strategy which is already used widely in schools.

Keywords: group work; zone of proximal development; constructivism

\footnotetext{
*Corresponding author. Email: dean.barker@ped.gu.se
} 


\section{Introduction}

If group work has not always been a central element of Physical Education (and Health HPE), ${ }^{1}$ then it has certainly become one in recent times (Ward and Lee 2005; Brock, Rovegno, and Oliver 2009). As a teaching strategy, group work fits neatly within constructivist approaches and features in curricular models such as teaching games for understanding (Griffin, Brooker, and Patton 2005; Butler 2006), sport education (Wallhead and O'Sullivan 2005; Hastie and Curtner-Smith 2006; Siedentop, Hastie, and van der Mars 2011), peer-assisted learning (Ward and Lee 2005) and cooperative learning (Dyson, Griffin, and Hastie 2004; Bähr and Wibowo 2012). Within these models, HPE teachers assume 'less directive and more facilitative' roles (Kirk and Kinchin 2003, 229) and students are expected to construct meaning (i.e. learn) without immediate instruction from the teacher. It is also frequently claimed that not only is group work an appropriate way to learn subject content but that it also results in the development of 'interpersonal skills' (Dyson 2001; Barker 2007; Casey and Dyson 2012).

In this paper, we propose that despite: (1) the widespread use of group work in HPE; (2) significant discussion surrounding HPE models that utilize group strategies; and (3) an extensive corpus of literature that deals with group work beyond the field of HPE (Slavin 1996; Johnson and Johnson 2003; Webb and Mastergeorge, 2003; Gillies and Kahn 2008; Gillies and Haynes 2011) group learning has received relatively little theoretical attention within HPE. As Ward and Lee (2005) contend, "the rationale for the use of peers to facilitate learning among students has not been as theoretically grounded as it has been practical' (220). In order to fill what we see as a significant lacuna, we propose a way of conceptualizing individual learning in peer interaction based on tenets of postVygotskian theory. By referencing three empirical instances, we illustrate the kinds of insights post-Vygotskian theory can generate. We conclude with suggestions for how this theory might inform practice.

\section{A scenario}

A senior HPE class has been working on a golf unit for six weeks. They have practiced golf skills, discussed rules and etiquette, and have looked at access issues in their community. After three sessions at a driving range, the class is now in a culminating lesson on a local nine-hole golf course. The students have formed groups and have set off at intervals. One group consists of four girls, three of which are relatively knowledgeable golf players. The fourth, Zara, has missed several lessons during the golf unit due to illness and is having little success. After the second hole, the three more capable girls begin to offer advice and encouragement. One suggests that she use an iron instead of a wood at the next tee. Another proposes that she modify her grip. On the next hole they tell her to keep her head down and reduce her backswing. 'Stay relaxed' one girl repeats. Zara attempts to adjust her movements accordingly but by the ninth hole, she is exhausted and frustrated. Her performance has not improved and the two hours seems to have been a waste of time. 'That's the last time I play golf', she thinks on her way home.

There are different ways to frame learning theoretically in this scenario. Situated learning, with its focus on the "various physical, social, and cultural dimensions of the context for learning' (Kirk and MacPhail 2002, 183 - see also Kirk and Macdonald 1998; Light 2006, 2011; MacPhail, Kirk, and Griffin 2008) has been used regularly in PE research and appears to be a useful way of making sense of the situation. From a situated learning perspective, we might claim that Zara's participation in the golf unit has not resulted in the mastery of 'goods' (knowledge, skills and dispositions - see Kirk and Kinchin 2003) that 
are internal to the practice of golfing. Although situated learning and concomitant notions of legitimate peripheral participation and communities of practice (Lave and Wenger 1991) provide a sophisticated means of thinking about how Zara might be becoming (or not becoming) a participant in a sporting community, they do not provide conceptual tools for looking at her local learning situation.

Piagetian ideas could also provide a useful framework for thinking through the immediate situation described above, even if they have been employed rarely in an analytic sense within HPE (see Rovegno and Dolly 2006, for a discussion of the extensive influence Piagetian theory has had on HPE teaching practice and curricula, and Lafont 2012, for a consideration of how Piagetian theory can be connected with group work in HPE). The notion of socio-cognitive conflict, or the idea that learners face tensions when their psychological constructs do not match (a) the conditions in which they find themselves or (b) the constructs of their peers, could be applied to the scenario in order to think about the differences between the girls' understanding of golfing technique. Traditionally, the idea of socio-cognitive conflict was based on the premise that interacting learners have the same level of expertise and was applied in cases in which learners had opposing responses for a task. Theorists have since extended Piaget's principles, proposing that conflict is not absolutely necessary for learning and that conflict resolution is not the only way for learning to occur (Darnis and Lafont, cited in Lafont 2012). Still, Piagetian principles tend to deemphasize differences in individual experiences (Lafont 2012), which in the golfing example are worth considering.

So while tools to analyze group learning do exist, they are not particularly common and sometimes have not been calibrated to deal with interactions at an interpersonal level. Ward and Lee's (2005) review - a review that serves as a useful stanchion for this paper suggests that peer-assisted learning is one of the more thoroughly researched areas in HPE yet they also conclude that (1) there is little discussion around theories of learning underlying the studies and (2) this body of research has consequently had little impact on the understanding of inter-student interactions more generally. Rovegno and Dolly's (2006) review of constructivist research in HPE reveals one investigation that focuses on social interaction as part of learning (Tjeerdsma 1998) and this paper deals with interactions between student teachers. A pragmatic perspective as outlined by Quennerstedt, Öhman, and Öhman (2011) and Quennerstedt (2013) could provide a useful analytic framework but to our knowledge this approach has not been employed to examine group work in PE. Ussher and Gibbs' (2002) research provides a further contribution to group work and has relevance to social interaction. Their paper delivers a succinct overview of Vygotskian theory and provides a thorough consideration of the potential implications for physical educators. Yet despite this contribution, Vygotskian theory has generated relatively little empirical and theoretical interest in PE research.

Given the lack of literature on inter-student learning in groups, the purpose of the next section is to outline some theoretical principles that we believe can complement situated and Piagetian learning perspectives and be used to conceptualize pedagogic activities like the one presented above. After this, we put these principles to work in an examination of empirical material.

\section{Vygotsky, social interaction and learning}

It is probably fair to say that while Lev Vygotsky's (1978) constructivist ideas have influenced HPE practices (Rovegno and Dolly 2006); his theoretical contributions have received little empirical attention within the field (see d'Arripe-Longueville et al. 2002; Ussher and 
Gibbs 2002, for two exceptions). This is unfortunate since his specific interest in how individuals relate to one another in learning situations and his emphasis on the importance of activity to learning make his work highly relevant to HPE practices.

Vygotsky understood learning itself to be a social enterprise where meaning is constructed in social relations and dialogue (Samaras and Gismondi 1998; Cheyne and Tarulli 1999). He proposed the notion of a zone of proximal development (ZPD) as

the distance between the actual developmental level as determined by independent problem solving and the actual level of potential development as determined through problem solving under adult guidance or in collaboration with more capable peers. (Vygotsky 1978, $85-86)$

Vygotsky used this idea to explain learning that takes place when children interact with their parents. Working with this idea, theorists have subsequently advanced modifications, commentary and clarifications. Hedegaard (1996) and Newman and Holzman (1993), for example, have suggested that the ZPD is often placed within a cognitive perspective but that it is more usefully understood as an active process rather than a psychological space that one can be 'in.' Hodkinson, Biesta, and James (2007) agree, suggesting that even within some post-Vygotskian theorizing there remains 'a concentration on cognition, rather than seeing learning as practical and embodied' (417) - see also Gredler and Shields (2004). Chaiklin (2003) and Gredler (2012) have argued that the ZPD was not initially concerned with task development, but rather with the social situation of cognitive development in general. They maintain that the social situation is a useful area of focus. A number of scholars have also pointed out that an unequal distribution of knowledge between actors of the kind posited in original parent-child studies will not guarantee learning and that the way in which learning takes place between experts and novices is complex - experts cannot simply make knowledge appear in learners' heads (Howe 2009; Radford and Roth 2011), or their bodies for that matter.

These points are important and we are mindful of these in our analysis of HPE practices. For us however, a post-Vygotskian framework based on more recent research (Brown and Ferrara 1985; Langemeyer and Roth 2006; Roth and Lee 2007; Roth and Radford 2010; Radford and Roth 2011) takes us beyond Vygotsky's original ideas in three important ways. First, such a framework attends to the way in which a ZPD is created collectively. In this respect, it stresses the importance of initial semiotic agreement as a prerequisite for learning. Second, it acknowledges the complexity of expert-novice relationships in a way that original Vygotskian work did not. Finally, a post-Vygotskian framework is more explicit with respect to how knowledge is constructed. These ideas are discussed in further detail below.

\section{(i) Collective consciousnesses}

Radford and Roth (2011) maintain that groups have traditionally been viewed in terms of ensembles of individuals where knowledge is transmitted from person to person. To circumvent individualistic approaches to group learning and the notion of simple knowledge transmission, Roth and Radford (2010) have suggested that a ZPD constitutes an activity where actors work to connect consciousness's (see Langemeyer and Roth 2006 for a useful discussion on consciousnesses). They contend that in a ZPD, a group has a shared consciousness, or as we prefer a shared communication, and that knowledge is brought into being collectively. As people attempt to enter into this activity, one person 'seeks the respective other through words and bodily 
actions and reactions, such as grasping, touching and pointing' (Roth and Radford 2010, 305). These scholars argue that it is when the object of knowledge emerges simultaneously (in the group's consciousness or communication) that learning in terms of ZPD occurs.

The idea of a collective consciousness is related to the Bakhtinian idea that in conversation, a person's utterances or actions never belong solely to that person. This is because it is only in the evaluation of an utterance that it will come to be defined (Bakhtin 1978). In this sense, utterances (and actions) in group situations are always shared by the participants of the particular event - they are intercomprehended. This has implications for the way we think about inter-student interaction and possibilities for learning. For a ZPD to be created, actors need to be prepared to enter into a shared world of significations (Roth and Lee 2007). Since individuals understand whether they have provided an appropriate response through the evaluation that results from that response, series of events cannot easily be prearranged. One person can never foresee precisely how others in the group will react to her/his action so neither the outcomes of group work nor how it will be played out can ever be entirely anticipated.

\section{(ii) Expert knowledge relationships}

Although Vygotsky's work was quite clearly based on the idea of an expert-novice relationship (Brown and Ferrara 1985), more recent work has sought to re-frame this relationship. Roth and Radford (2010) suggest that ZPDs can be understood as an interactional achievement that allows all participants to become both teachers and learners. They claim that it is unnecessary and ultimately unproductive to think of participants in fixed expert-novice terms because this view conceals how both experts and learners must display cultural competence to participate in communication in ways that will result in learning. An eight-year old 'learner' receiving instructions about how to hit a backhand shot from his tennis coach, for example, needs to communicate that he understands (or does not understand) what a backhand shot is, what changing grip means and so on. Indeed, if the boy does not communicate to the coach that he needs further explanation - i.e. if he does not teach the coach what he needs to learn, knowledge development will be compromised. Indeed, in a productive ZPD, we might hypothesize that this kind of two-way learning process would be common as students (in an institutional sense) explicitly communicate to their teachers (again, in an institutional sense) their understanding, rather than let teachers guess the reasons behind specific actions.

\section{(iii) Knowledge and learning as reaching agreement}

Throughout this exposition, we have talked about knowledge and how it might be 'brought into being.' It is useful to consider what we mean by 'knowledge,' especially if we are to avoid thinking about it as a kind of concrete substance that can be transmitted. Before doing so, it is worth pointing out that knowledge has traditionally been understood as something that we have rather than something that we do (Sfard 1998; Hodkinson, Biesta, and James 2008) and this view has been institutionalized in schools and universities through practices such as examinations (Hodkinson, Biesta, and James 2008).

With this in mind and in line with sociocultural learning theory (Hodkinson, 2005; Hager and Hodkinson, 2009), we are going to propose that knowledge in relation to a ZPD as activity is fundamentally tied to the notion of agreement. This fits reasonably comfortably with Radford and Roth's (2011) notion of 'inherently collective significations' (231). It is in the process of reaching agreement on how something should be done or 
thought about that knowledge is created (Howe 2009 provides a discussion and criticism of this proposition). In one respect, knowledge-as-agreement sounds somewhat counterintuitive. In another respect, this idea fits with many current 'knowledge practices,' where knowledge is organized into disciplines where agreed upon principles serve as the basis for knowledge activities.

Thinking about agreement and 'knowledging' at an intra-group level has at least two implications. First, the process has to do with persuasion. For someone to enter into an agreement with someone else, they need to be convinced that the other person is acting in an effective or successful way. Second, if we take knowledge as something that you are, or rather become (Hodkinson, Biesta, and James 2008), then doing different knowledge is about being different. Roth and Radford (2010) suggest that learning has to do with 'the possibilities that become available to the participants for thinking, reflecting, arguing and acting in a certain historically contingent cultural practice' (305).

\section{Data production procedures}

The empirical material used in this article was generated with eight different HPE classes in eight different lower and upper secondary schools in Sweden. Schools were selected in a way that maximized variation and were distributed across four geographic locations with varying sizes and types of communities. Classes were selected to further increase variation and differed with respect to level (pupils' ages ranged from 13 to 18 years), profile (general profile, sports profile, health profile) and activities or content. Observations and interviews were used to generate data (for a more thorough description, see Quennerstedt et al. in press). Teachers and students were informed that lessons would be observed but were not asked by the researchers to act in particular ways (e.g. to teach with a certain style, or in the pupils' cases, to behave well). Still, like Barker, Barker-Ruchti, and Pühsel (2013), we are reluctant to call these 'naturally occurring' lessons as the researchers' presence surely affected the lessons in some ways.

\section{Observations}

Observations consisted of at least three video-recorded lessons with each of the eight classes. Video recording at each school was done by two members of the research team (two members were responsible for the two schools in their geographic location). Video recording involved using two cameras: one stationary and the other mobile. The stationary filming maintained a wide-angled focus but also panned to film different parts of the teaching setting. This filming provided a sense of what was taking place in the entire class but, with the exception of when a teacher was speaking to the entire class, did not capture dialogue particularly effectively.

Mobile filming focused on specific individuals or groups of individuals. Between two and five individuals were generally in the frame at any one time and filming was done with the intention of capturing sequences in which pupils worked with a specific problem or on a specific task. In one of the sequences below, for example, a group of three students attempted to do a handstand against a wall. The sequence started with the students arriving at the work station and finished when they moved on to another task. Due to the proximity of the camera to students, audio material could be obtained and detailed transcripts of speech exchanges were produced. Interviews were also conducted with three students and the teacher from each class. While the teachers' comments help to contextualize the interactions, they add little to the theoretical advance. As a result, they will not be considered in detail here. 


\section{Key incidents and data analysis}

In connecting theory and empirical material, Emerson's (2004) notion of key incidents was utilized that stemmed from our theoretical framework. For the purposes of this investigation, two kinds of key incidents were of interest. The first comprised a series of events in which: (1) two or more students began a dialogue in order to complete a task which they could not immediately do; (2) two or more of the students engaged in a relationship where one was granted expertness, at least temporarily and (3) collective communication ended in member talking about or doing the activity in mutually compatible ways. These conditions corresponded to the post-Vygotskian postulates mentioned above and were sufficient in our view to signal the creation of a ZPD. The second kind of incident fulfilled the first criteria but not the second or third - i.e. the students were interacting but were not involved in collective signification or doing an activity in mutually compatible ways. We took these incidents as examples of group work in which a ZPD was not being created. Of course, there were many occasions during the lessons where either of these two sets of conditions was fulfilled. We captured only a fraction that occurred during the lessons on film and of those that we did record, only three are presented here as illustrations of the points made in the article. As a consequence, we are not arguing for statistical representativeness. We are claiming, however, that the incidents examined below can tell us something about learning that occurs during inter-student interactions in HPE lessons. The incidents work to complement rather than verify the theoretical tenets outlined above, namely, that: (i) individuals engage in collective communication during effective group work; (ii) a consideration of knowledge relationships are important and (iii) learning can be thought of as reaching agreement or consensus. The incidents that are considered here have been selected not because they are typical but because they show how inter-student interactions can occur with diverse outcomes.

\section{Key incident one}

The first incident illustrates key ideas (i), (ii) and (iii), and took place in a co-educational, year eight class (students aged 14 and 15 years). The students had been working on Swedish folk dance ('Schottis') but in this lesson they were given the opportunity to create their own dance sequences. Before the illustration, the teacher demonstrated different dance moves the students could use in their pieces. In terms of lesson aims, the teacher said that he would like the students to: develop a stock of different moves which the students could use to dance; produce a dance sequence from these moves; learn how their bodies work; learn what dance is and can be, and learn 'what you do when you are dancing.' In this particular part of the lesson, the students have been asked to work to the music provided (the song Soulja Boy) in friendship groups of between four and six people. The sequence needed to include five different kinds of movement and take place in 8's (two bars of four). The group examined here consisted of five girls. The interaction unfolded in the following manner:

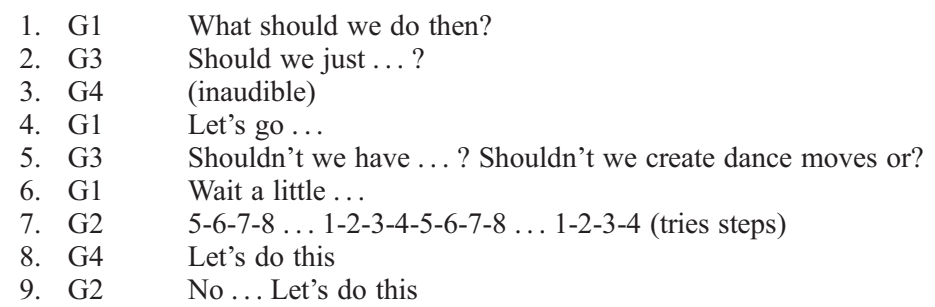


10. G4 No something else...

11. G1 Hey ... I've come up with a dance... we just stand like this

12. G2 Like this! (shows steps) 1-2-3-4-5-6-7-8

13. G5 What shall we do?

14. G2

15. G3

16. $\mathrm{G} 2$

17. G3

18. G2

19.

20. G3

21. G2

22. G3

23. G2

24.

25. G3

26. G2

27.

28. G3

29. G2

30.

31. G4

32. G2

33. G4

34. G2

35.

36. G3

37. G4

38. G1

39. G4

40. G2

41.

Klara... You're good at this ... you are a dancer (turns to G3)

So are you (turns to G1)

Like this then? (shows with G4) 1-2-3-4-5-6-7-8 . . 1-2-3-4-5-6-7-8

I don't get it!

But then we move our hand forward like this when we go forward . . 1-2-3-4-5-6-7-8

(shows steps)

I don't get it ... show the steps

Like this ... check it out!

If you stand in front of us ... like this ... with your back towards us ... do you get it?

Like this ... 1 ... (shows) . . 2 . . No ... wait ... wait ... yes. 1-2 (shows and the other

follows) And then back with ... like this $4 \ldots$ and you walk forward with this 5-6.

No then it is ...

No ... the other way around ... Yes ... It is this in the back ... so you go forward with this, like this.

Aha!

When you go forward ... well check this out 1-2-3 n 4 (shows steps and the others follow) 5-6-7 n 8 .

7 n 8

1-2-3 n 4 . . 5-6-7 n 8 (shows steps)

How? ... 1 n 2

No ... look ... like this. Go forward with this (shows). 1 .. 2 (shows). Then you jump back with that (shows). $3 \mathrm{n} 4$. Then we go forward ... wait (shows). 5-6-7 n 8.

That's really good ... that is an 8

What did you say?

I have forgotten how to do it!!

1-2-3-4

So you go forward with that ... that. No you should take that hand forward ... no, start with that. (G2 helps G4 by taking her hand). So do you go forward with that (pointing at the foot).

43. $\mathrm{G} 2+\mathrm{G} 4$ 5-6-7-8

44. G2 Yes!

45. G4 I get it!

46. G4 1-2-3-4-5-6-7-8

47. G3 But tell me what arm you use? (turning to G2)

48. G2 It was this arm (shows). You go forward with the right foot

49. G4 5-6-7-8

50. G3 Like this? (turning to G2)

51. Gs(?) 1-2-3-4-5-6-7-8

52. G2 Okay ... shall we start?

In lines 1-16 we can see the process by which the girls are 'seeking each other' (Roth and Radford's (2010) collective consciousness). Both conversation and action are disjointed and the girls appear to be almost talking past one another. These lines also contain a series of tentative attempts to establish who is in the know, the expert in the relationship (Roth and Radford 2010), probably the most explicit being G2's suggestion that G3 (Klara) is good at dancing. With respect to expertise, line 17 is critical because it is at this point that one of the girls (G3) responds and asks another girl (G2) to show her how to proceed. By doing this, she demonstrates her willingness to listen, take on a learner position (Brown and Ferrara 1985) but most importantly, she grants G2 an expert role. These two girls continue for a series of expert-learner turns until in line 28, G3 exclaims 'Aha!,' representing very clearly a moment where the two students reach a mutual understanding (Roth and Lee 2007) of what they are doing. It should also be noted that after G2 has taken on an expert role, G4 and eventually G1 also take on learner roles and direct their questions to 
G2. Similar to G3's 'Aha' moment, G2 and G4 count and move in unison in line 43 and both acknowledge the success of 'finding each other' in lines 44 and 45 with 'Yes' and 'I get it!.' Again, this is not the realization of procedural knowledge that exists beyond the group but rather the realization that they understand each other in shared communication. While not in an expert position, G3 nevertheless directs the activity further:

1. G3 What should we do after that then? (Three of the girls try the steps)

2. G1-3 1-2-3 n 4 .. 5-6-7 n 8

3. G2 We should maybe...

4. G4 $1 \ldots 2$ (tries other steps)

5. G2 Like this ... (tries new steps) .. 1 . 2.. like this

6. G4 Like this? $1 \mathrm{n} 2 \ldots 3 \mathrm{n} 4$

7. G2 Yeees! That's good. Can I see? (G4 shows steps G2 G1 tries to follow ... G3 shows

8. additional steps)

9. G2 Yees! ... 5-6-7-8

10. G1 Yes that's ... Yes ... what did you do?

11. G3 This ... sort of (new moves with arms).

12. G2 Yes let's do that one

13. G1 How do you do it? (waves to someone)

14. G2 That one is popular

15. G1 How did you do it?

16. G3 (shows slowly) like this ... bam! Spin ... is done like this (shows). Bam ... bam ... bam!

17. G1 Yes like this! (Tries and turns to G3)

18. G3 It is like ... bam ... bam ... bam! So ... here it is. (shows and the others follow)

19. G2 So ... bam-bam-bam? (shows).

20. G3 Yes ... bam-bam-bam! (shows).

21. G2 It is soo tough with the arms ... 1-2-3-4 .. how should the arms be?

22. G3 Like this (shows)

23. G4 Steady ... spin (shows)

24. G3 You spin (shows)

25. G1 Yes, but after that you should go back (Everybody tries the new move).

In this part of the sequence, the girls continue to interact and are actively pursuing the responses of the others ('Like this?'), characteristics that for Roth and Lee (2007) are crucial for the production of a ZPD. It is interesting that as they do this, the expert position changes. In line 6, G4 offers four counts and G2 who has been in an expert position listens and asks for clarification. Immediately after, G1 asks G3 how she moved her arms and G3 takes on an expert role. G3 and G2 then engage in an interactive sequence where G3 assigns her movements noises and invites G2 to engage in the movements as well as the noises (which she does). The result is that shared signification in terms of collective agreements (Roth and Lee 2007) occurs both verbally and corporeally.

\section{Key incident two}

The second incident illustrates the importance of knowledge relationships and shows how learning can be thought of as reaching agreement (key ideas (ii) and (iii)). The incident took place in a co-educational class with students in their first year of upper secondary school (aged 16-17). Prior to the lesson, the teacher had asked the research team if there was anything in particular that she should teach. Our response was that it would be interesting to see student-centered lessons. The class had done apparatus gymnastics earlier in the term and in this particular lesson, students were given the opportunity to re-visit these activities and practice what they had learned in groups. Although the teacher had set up three stations in the gymnasium with task sheets and drawings of activities (different kinds of skipping and balances for example), she began the lesson with a 
relatively detailed set of instructions of what to do at each of the stations. In the incident described below, eight students have been grouped together by the teacher and appear to include two 'friendship sub-groups' (a boys 'group and a girls' group). They are attempting to build a human pyramid:

1. B1 We must have three in the bottom.

2. G1 Isn't it better with four, three and then one. [no rise in intonation].

3. G2 Yeah, okay. (Four students go down on the hands and knees forming the bottom layer). But

4. who'll be at the top then?

5. G3 Not me.

6. G1 Now, you are at the top (refers to G4, when all the others stand on all four on each other's

$7 . \quad$ backs).

8. G4 Oh, I'm not going to sit [at the top]. (Directed at the teacher. The teacher walks up and

9. instructs).

10. T Here, if you say, it is best to sit there (points to one pupil's lower back), and similarly this is

11. where you should hold (and points to the pupil's shoulders). So that you do not hold on the

12.

13.

14.

15. B2 Come on Jasmin. (refers to G4 who should be at the top)

16. G4 No I dare not, should we change places?

17. G1 Okay (G1 changes places with G4).

18. G4 But I can be at the bottom okay, it is not a problem (the pupils rise up while waiting for the 19. discussion to finish).

20. B1 Shall we try again? Somebody just lay over.

21. G1 We are too many.

22. G5 No, but we are not coming a step further.

23. G2 But we'll try one more time. Tight again this time. (The group tries).

24. G3 Well ... it feels very ....

25. G4 I do not dare.

26. G1 But hurry.

27. G4 But why shall I do it and why don't I get a good position?

28. B1 We're not getting anywhere here.

29. T Then you have to find another way ... or you have to find something else to do.

30. B2 Okay, I can be at the top then.

31. Girls Yesss...

32. B2 Okay, are you in now, or(?), great ... I'm trying now ... Now you have to crowd together.

33. B1 Come on Anton (B2 makes a brief, tentative attempt to get on to the top of the second layer, 34.

35. B2 If you'd had your shoulders together it would have been much easier.

Here it is significant that the students come to some sort of agreement about the structure of the pyramid (i.e. four people, three people and then one person) quickly. Until line 17, however, they do not decide on who will be the person at the top - G4 says twice that she will not go at the top, at first directing her comment at the teacher (in effect inviting the teacher to the group). The others continue making the base of the pyramid without acknowledging the lack of agreement concerning the peak. The oversight appears relatively obvious when we read the transcript but when the teacher arrives, she is unaware of the preceding conversation. As a result, she provides some technical advice which in essence does not move the group closer to the completion of the task. By the time the decision of who will be on top is reached, several group members have begun to withdraw from the activity and the conditions for a ZPD (at least in terms of willingness to be task-oriented, Roth and Lee 2007) have started to recede. In line 20, one boy asks if they want to try again and G2 does not want to.

Also important is that there are few instances of expert-learner relationships being created. In line 6, G1 tells G4 to go at the top of the pyramid but G4 does not. Indeed, 
no-one is granted 'expertness' until B2 asks in line 30, 'Are you in now?' as he is getting ready to climb to the top of the pyramid. And even when in agreement about who will be at the apex, there is misunderstanding about how the people should be holding themselves. Following the unsuccessful attempt B2 claims that those on the lower layers should have positioned themselves differently.

It would be easy to assume that the students were unsuccessful with the pyramid task because they were unprepared to listen to one another. This probably was a contributing factor and may have been related to the size of the group (eight members compared with five in the first incident and three in the third). However, in our view the presence of the teacher was also significant. Even though in accordance with constructivist principles, she says little and allows students space to construct their own meanings, she occupied an expert role. When she joined the group, she assumed an authoritarian voice, telling the students how to work safely. When B2 says that he will go on top, it is a learner response to one of the teacher's comments (line 29). This occupancy appears to make it difficult for one or more of the students to take expert positions and move the group ahead with its task. Paradoxically, the teacher is only prepared to give safety tips and does not want to tell the students how to complete the task. In this respect, her presence presents the group members with a catch 22 .

\section{Key incident three}

This incident illustrates how individuals create a collective communication and how a consideration of knowledge relationships can be considered important (key ideas (i) and (ii)). The incident occurred in a lower secondary school class with students aged 13 and 14. This particular lesson takes place in the small gymnasium. The students have the opportunity to practice gymnastic-type activities for the first half of the lesson and the groups rotate from the rings to the mini-tramp to the thin mats. The teacher splits the class into three groups of approximately seven. Each group contains sub-groups based on friendship and the individuals' competence in gymnastics varies substantially. The teacher begins the lesson with basic instructions about what to do at each station - essentially, the students are to improve their performances of motor skills by practicing skills which have been covered previously - and there is no further instructional material at the stations. He stays at the mini-tramp station which he states is the most risky and therefore most in need of his supervision. The sequence below occurs on the thin mats where two girls are practicing head stands and hand stands. In line 16, they enlist the help of a third.

1. G1 You can try, I will stand here and help you ... You should keep your hands as close to the

2. wall as possible.

3. G2 Okay wait. One ... two, help me now okay?

4. G1 Yeah! You will only (clap) against the wall ...... What was that?

5. G2 I'm too scared ... Okay let's do a headstand.

6. G1 What shall we do? Stand on the head?

7. G2 Yeah, do a headstand.

8. G1 Can you do it?

9. G2 Yeah (almost does a headstand)

10. G1 Oh my god, shall I help you?

11. G2 Leaned over too much ...

12. G1 Okay, shall I stand on my hands now?

13. G2 Yeah.

14. G1 No, I'm too scared.

15. G2 Shall I help you? Come on!

16. G1 But I'm too scared, you will have to help me ... (shouts at her friend) IDAA! 
17. G3 YES!

18. G1 Can you come here?

19. G3 Yeah. (G3 crosses the gymnasium to join G1 and G2)

20. G2 Let's try ... You know, no guys are skillful.

21. G1 (to G3) Can you help us do a handstand? ... (G1 starts to attempt a handstand) I'm too

22.

23. G1

24. G3

25. G1

26.

27.

28. G3

29.

30. G1

31. G2

32. G3

33.

34. G2

35. G1

36. G3

37. G3

38. $\mathrm{G} 3 / \mathrm{G} 1$

39. G3

40. G1

41.

42. G3

43. G2

44. G1

45.

scared ... (G3 makes a handstand against the wall)

Yeah, but you can do this?

Try it.

You have to help me then ... oh god ... I will try it once (makes a slow run-up and starts over again) ... Okay, help me now ... Okay, are you ready? Let's go. (G3 and G2 help on either side. G1 is able to hand stand against the wall).

Great! Really good! (G2 gets ready and tries while G1 takes her old position and helps her).

Pretty close I think, that's good. (G2 readies herself for another attempt, but is hesitant). But I am not going to do it so fast.

But stand like this from the beginning (points out that she can begin with her hands on the floor instead of standing up position).

No no no (gets ready for a run-up again).

Do it pretty fast and try to have some kind of tension in the legs.

Just hold your arms, try it once by yourself, and sort of just throw up your legs. (G2 tries). That's right ...

And a little bit closer. (G2 tries with a run-up but again pulls out).

A little bit closer. It doesn't need to be much closer, you just have to kick up your legs.

Try to be as close as possible, you will not hit your head. (G2 tries and manages it with help)

Good look, look, look. And lean your legs against the wall.

I would like to try it again

But you have to get even closer. Try to be there with your hands (pointing with the feet to Where G2 should have the hands). Because then you will not be so curved (G2 tries and manages it).

In this illustration G1 begins by assuming the expert role and providing G2 with technical suggestions. G1 loses her 'expertness' as G2 decides to attempt a headstand instead of a handstand (G1 is not sure how to help her with this new task). Line 16 marks the point that G1 realizes that neither she nor her partner can work in the expert role and that a new input is required. Once G3 has been summoned and has joined G1 and G2, G1 asks for her help (line 21). G3 almost simultaneously performs a neat handstand against the wall, both actions we would argue serve to establish the expert-novice positions. From this point, there are a series of turns where G3 helps G1 with her handstand. When G1 manages, G3 responds with a small celebratory exclamation. G2 is still unable to perform the task and it is interesting to listen to the exchange from line 32 onwards in terms of agreement or lack of agreement. G1 and G3 agree that speed is important - the performer must 'throw' her legs up on to the wall. G2 disagrees, saying that she will do it slowly. Her disagreement is made explicit in both her words and her body. Indeed, this is a sticking point and appears to be the difference between the 'handstanders' and the 'non-handstander.' In line 43, G1 appears to recognize that reassurance may be an effective way to persuade $\mathrm{G} 2$ to execute the movement with speed. This seems to work and once G2 has performed the handstand with speed, the 'expert girls' move on to another aspect of the task.

\section{Discussion}

By way of key incidents, we have illustrated the kinds of features to which post-Vytgotskian principles might draw our attention in practical contexts. The broad argument that we develop in this section is that this perspective encourages us to reconsider how we facilitate group work. 
Specifically, we focus on: (1) peer teaching and the notion of expertness; (2) what can and should be accomplished with group work; and (3) the role of the teacher during group work.

The readings of the incidents invite us to consider roles in knowledge relationships (Roth and Radford 2010). Early sociocultural understandings of peer-assisted learning suggested that more able peers guide or help less able ones (Ward and Lee 2005). This approach is supported by the sport education model in which particular students learn to be expert in particular areas and then guide others (Kirk and Kinchin, 2003). In effect, this thinking leads to asymmetrical relationships, which according to post-Vygotskian thinking are necessary for learning (Radford and Roth 2011). At the same time, this kind of approach overlooks the reciprocal nature of learning relationships and privileges the expert role as the active role. Incidents one and three contain clear examples of students in novice roles actively seeking help and guiding the learning process. Indeed, it was in these two incidents that the activity seemed to 'work' and the groups successfully reached agreement on how the task could be completed. These kinds of observations have led educational theorists to note effective help-seeking behaviors (Gillies and Kahn 2008). Webb and Mastergeorge (2003), for example, suggest that asking precise questions and persisting in seeking help are important for promoting learning during dialogic exchanges and that it is essential for teachers to give students opportunities to apply explanations that are received. Irrespective of whether the students in incidents one and three had learned these kinds of behaviors or engaged in them by chance, they encourage facilitators to prepare students for help-giving and help-seeking.

Further, but still related, the incidents illustrate the transitory nature of expert-novice relationships. Rather than being a product of what someone has (in terms of knowledge, ability or role), expertness might more fruitfully be seen as contingent and changing (Roth and Radford 2010). Thinking about experts and novices in more fluid, flexible ways could encourage pedagogues to reconsider how they define group tasks and in particular what they expect to happen between students. The teachers in this project rarely mentioned interpersonal aspects of activities in their pre-task briefing, instead focusing on task-relevant information. This may not be that surprising given the age of the students (i.e. the teachers simply assumed that high school students could learn from each other), nor is it uncommon - see, for example, Casey and Dyson (2012), who suggest that teachers rarely plan for outcomes such as cooperation and leadership and are more likely to treat them as 'foregone conclusions' (167). The data presented here suggested haphazard progression where learning based on interpersonal relationships required effort and could not be guaranteed. While others have stressed the importance of face-to-face interaction, a focus on interpersonal skills, and the provision of adequate time for learning to occur (Dyson 2001, Dyson and Casey 2012), in line with Gillies and Haynes (2011), we would add that the construction of interpersonal relationships and the construction of content knowledge are intimately connected. Being able to decide on an effective golf swing in a situation such as the one described at the beginning of the paper may, depending on the circumstances, depend as much on a person's ability to communicate with those around them as on their motoric capacity. This is an interesting proposition that challenges the common sense division between technical and social skills and invites us to more clearly focus on how students can interact in 'learning ways.' While an exploration of this issue is not within the scope of this paper, such a focus might be facilitated in practice by students reflecting on their own interactions or watching others' interactive sequences and then practicing interpersonal strategies in cooperative situations.

Second, a post-Vygotskian interpretation draws attention to the intended outcomes of group work. If we take the notion of collective communication (Langemeyer and Roth 2006) 
seriously, then we must entertain the idea that students working in groups will engage in activities and with each other in ways that they find appropriate or acceptable. If knowledge is agreed upon in interaction, then learning could take place in any direction, not just from 'less skilled' to 'more skilled' and could be multi-dimensional in that students could learn in the motoric, interpersonal and/or affective domains. Learning outcomes may not completely or even closely align with those that the pedagogue has in mind. As Howe (2009) notes, this is an interesting proposition for teachers, especially in contexts where prescribed learning objectives and teacher accountability are becoming increasingly important. In the second key incident, students spent a great deal of time discussing a task but were neither active nor successful in their attempts to complete it. In this sense, effective group work that involves promotive interaction and group processing or reflection (Dyson and Casey 2012) could be seen as risky or inefficient (in terms of health outcomes, e.g. see Gard and Wright 2005). And at the same time, the idea that uncertainty in learning experiences might be educationally generative (Helsing 2007) as well as the notion that students in HPE might create novel ways of 'doing HPE' is quite appealing for us. It speaks to questions of relevance and sustainability that have been recurrent in the field (Kirk 2010).

Finally and related to the second point, a post-Vygotskian reading of the incidents above invite us to consider the role of the teacher in creating collective communications. Such a reading highlights the challenging 'facilitative' (Kirk and Kinchin 2003) task faced by teachers as they attempt to enter into communications with students while simultaneously encouraging students to communicate with each other - see Casey and Dyson's (2012) discussion of student independence and the paradoxical situation in which it places the teacher. The teachers in the examples above tended to work with a kind of 'front-load and support' model where they provided input, gave the students time to work alone and (possibly) circulated to provide support where needed. The three incidents here suggest that: (1) teacher support is not always necessary for learning to take place (the teacher did not join the groups in incidents one and three); and (2) teacher involvement is not always helpful, as the second example demonstrated. Rather than suggesting that teachers should play smaller parts in group work activities, in line with Bähr and Wibowo's (2012) contention that teachers intervene too often and too invasively during group work, we would propose that they might benefit by carefully considering how and when they become part of groups' collective communications. If students have learned how to engage in reasoned argumentation and have effective dialoguing skills - and of course, the teacher could be expected to have helped the students to develop these - the teacher might not need to become involved in the group activity. Teachers might try to ascertain the nature of shared communications before they enter into them. We recognize this could be difficult given that by simply being present, teachers both communicate and influence communication; nonetheless, we would contend that with experience gauging elements of dialogue such as the quality and quantity of questions being asked (see Gillies and Kahn 2008) could help teachers to intervene more sensitively. They might attempt to see whether group members are other-oriented, and if not, endeavor to find out why. And they might try to examine interactions in terms of consensus and see what is agreed upon and what is not before they make suggestions. In our minds, these suggestions revolve primarily around listening but gain importance in light of teachers' privileged access to talking space in the classroom.

\section{Concluding thoughts}

We began this exposition with a scenario in which a pupil struggled to learn sport-specific (golfing) skills in the presence of more capable peers and in the absence of a teacher. We 
proposed that this kind of situation is common in HPE and that physical educators should consequently have a good understanding of how learning in interactions takes place if they are to facilitate it successfully. Using a post-Vygotskian perspective, this particular scenario could be read as follows: knowledge asymmetry exists within the group but this is not enough to guarantee a certain kind of learning. The learners attempt to, but do not succeed in, creating a collective communication and hence a ZPD. The novice in the situation does not manage to express what or how she needs to learn and hence does not become an expert with respect to her own learning. The result is that neither the verbal nor the corporeal agreement that would evidence learning is produced within the course of the activity.

A teacher working with the group might make various pedagogical changes to provide an alternative outcome. She might, for example, decrease the number of students in the groups to increase the chances of communication being conducted in a collective manner. She might work with the students prior to the activity, focusing on effective help-seeking behaviors and on how these might be useful in physical activity settings. She might also acknowledge that this activity has the potential to proceed in quite a number of ways. She may hope that the activity will end with each student experiencing success; however, she might recognize that the frustration accompanying lack of agreement may lead to learning in the future. In other words, it may provide the group members with ideas for how to create learning situations in the future. In this respect, the teacher has an important role to play in framing the pedagogical experience.

We have alluded to some of the implications such an approach might have for practice; however, this area could sustain further attention. Specifically, we would like to see the principles discussed here employed in a more intentional and pedagogic sense and examine the kinds of interactions that result. Also interesting would be an analysis that more explicitly incorporates a focus on corporeal communication. We are aware that this exposition, like much post-Vygotskian scholarship (Radford and Roth 2011), has been based largely on the transcripts of verbal exchanges. More attention could be paid to how bodies are involved in interaction and how these correspond to speech acts. This would seem to be a highly relevant aspect of HPE that is yet to be researched. Finally, it may be generative to explore how and why students are afforded expert status by their peers. In this respect, the micro-elements of power relations and pedagogical persuasion in HPE could be a useful topic to investigate.

\section{Acknowledgements}

This research was conducted within the project 'Physical Education and Health - a Subject for Learning?' funded by the Swedish Research Council, grant number: 2010-5182. The authors would like to thank Håkan Larsson, Inger Karlefors, Marie Öhman, Karin Redelius and two anonymous reviewers for insightful comments with earlier drafts of this paper.

\section{Note}

1. In Sweden, where this research was conducted, the title of the school subject is Idrott och hälsa or physical education and health.

\section{References}

Bähr, I., and J. Wibowo. 2012. "Teacher Action in the Cooperative Learning Model in the Physical Education classroom." In Cooperative Learning in Physical Education: A Research Based Approach, edited by B. Dyson and A. Casey, 27-41. London: Routledge. 
Bakhtin, M. 1978. The Formal Method in Literary Scholarship: A Critical Introduction to Sociological Poetics. Baltimore, MD: John Hopkins University Press.

Barker, D. M. 2007. "Reconsidering Teamwork." Quest 59 (4): 415-427.

Barker, D., N. Barker-Ruchti, and U. Pühse. 2013. "Constructive readings of interactive episodes: Examining ethics in physical education from a social constructionist perspective." Sport, Education and Society 18 (4): 511-526.

Brock, S. J., I. Rovegno, and K. L. Oliver. 2009. "The Influence of Student Status on Student Interactions and Experiences During a Sport Education Unit." Physical Education and Sport Pedagogy 14 (4): 355-375.

Brown, A., and R. Ferrara. 1985. "Diagnosing Zones of Proximal Development." In Culture, Communication, and Cognition: Vygotskian Perspectives, edited by J. Wertsch, 273-305. Cambridge: Cambridge University Press.

Butler, J. 2006. "Curriculum Constructions of Ability: Enhancing Learning Through Teaching Games for Understanding (TGfU) as a Curriculum Model." Sport, Education and Society 11 (3): $243-258$.

Casey, A., and B. Dyson. 2012. "Cooperative Learning in Physical Education." In Cooperative Learning in Physical Education: A Research Based Approach, edited by B. Dyson and A. Casey, 166-175. London: Routledge.

Chaiklin, S. 2003. "The Zone of Proximal Development in Vygotsky's Analysis of Learning and Instruction." In Vygotsky's educational Theory in Cultural Context, edited by A. Kozulin, B. Gindis, V. Ageyev, and S. Miller, 39-64. Cambridge: Cambridge University Press.

Cheyne, J. A., and D. Tarulli. 1999. "Dialogue, Difference and Voice in the Zone of Proximal Development." Theory and Psychology 9 (1): 5-28.

d'Arripe-Longueville, F., C. Gernigon, M. L. Huet, M. Cadopi, and F. Winnikamen. 2002. "Peer Tutoring in a Physical Education Setting: Influence of Tutor Skill Level on Novice Learners' Motivation and Performance." Journal of Teaching in Physical Education 22 (1): 105-123.

Dyson, B. 2001. "Cooperative Learning in an Elementary Physical Education Program." Journal of Teaching in Physical Education 20 (3): 264-281.

Dyson, B., and A. Casey, eds. 2012. Cooperative Learning in Physical Education: A Research Based Approach. London: Routledge.

Dyson, B., L. Griffin, and P. Hastie. 2004. "Sport Education, Tactical Games, and Cooperative Learning: Theoretical and Pedagogical Considerations." Quest 56 (2): 226-240.

Emerson, R. M. 2004. "Working with 'Key Incidents'.” In Qualitative Research Practice, edited by C. Seale, G. Gobo, J. Gubrium, and D. Silverman, 427-442. London: Sage.

Gard, M., and J. Wright. 2005. The Obesity Epidemic: Science, Morality, and Ideology. London: Routledge.

Gillies, R., and M. Haynes. 2011. "Increasing Explanatory Behaviour, Problem-Solving, and Reasoning within Classes Using Cooperative Group Work.” Instructional Science 39 (3): 349-366.

Gillies, R., and A. Kahn. 2008. "The Effects of Teacher Discourse on Student Discourse, ProblemSolving and Reasoning During Cooperative Learning." International Journal of Educational Research 47 (6): 323-340.

Gredler, M. E. 2012. "Understanding Vygotsky for the Classroom: Is It Too Late?" Educational Psychology Review 24 (1): 113-131.

Gredler, M., and C. Shields. 2004. "Does no One Read Vygotsky's Words? Commentary on Glassman." Educational Researcher 33 (2): 21-25.

Griffin, L. L., R. Brooker, and K. Patton. 2005. "Working Towards Legitimacy: Two Decades of teaching Games for Understanding." Physical Education and Sport Pedagogy 10 (3): 213-223.

Hager, P., and P. Hodkinson. 2009. "Moving Beyond the Metaphor of Transfer of Learning." British Educational Research Journal 35 (4): 619-638.

Hastie, P. A., and M. D. Curtner-Smith. 2006. "Influence of a Hybrid Sport Education - Teaching Games for Understanding Unit on One Teacher and his Students." Physical Education and Sport Pedagogy 11 (1): 1-27.

Hedegaard, M. 1996. "The Zone of Proximal Development as Basis for Instruction." In An Introduction to Vygotsky, edited by H. Daniels, 223-247. London: Routledge.

Helsing, D. 2007. "Regarding Uncertainty in Teachers and Teaching." Teaching and Teacher Education 23 (8): 1317-1333.

Hodkinson, P. 2005. "Reconceptualising the Relations Between College-Based and Workplace Learning." Journal of Workplace Learning 17 (8): 521-532. 
Hodkinson, P., G. Biesta, and D. James. 2007. "Understanding Learning Cultures.” Educational Review 59 (4): 415-427.

Hodkinson, P., G. Biesta, and D. James. 2008. "Understanding Learning Culturally: Overcoming the Dualism Between Social and Individual Views of Learning." Vocations and Learning 1 (1): $27-47$.

Howe, C. 2009. "Expert Support for Group Work in Elementary Science: The Role of Consensus.” In Transformation of Knowledge Through Classroom Interaction, edited by B. Schwarz, T. Dreyfus, and R. Hershkowitz, 93-104. London: Routledge.

Johnson, D., and R. Johnson. 2003. "Student Motivation in Cooperative Groups: Social Interdependence Theory." In Cooperative Learning: The Social and Intellectual Outcomes of Learning in Groups, edited by R. Gillies and A. Ashman, 136-176. London: Routledge.

Kirk, D. 2010. Physical Education Futures. London: Routledge.

Kirk, D., and A. MacPhail. 2002. "Teaching games for understanding and situated learning: Re-thinking the Bunker-Thorpe model." Journal of Teaching in Physical Education 21 (2): 177-192.

Kirk, D., and G. Kinchin. 2003. "Situated Learning as a Theoretical Framework for Sport Education." European Physical Education Review 9 (3): 221-235.

Kirk, D., and D. Macdonald. 1998. "Situated Learning in Physical Education." Journal of Teaching in Physical Education 17 (3): 376-387.

Lafont, L. 2012. "Cooperative Learning and Tutoring in Sports and Physical Activities." In Cooperative Learning in Physical Education: A Research Based Approach, edited by B. Dyson and A. Casey, 136-149. London: Routledge.

Langemeyer, I., and W. Roth. 2006. "Is Cultural-Historical Activity Theory Threatened to Fall Short of its Own Principles and Possibilities as a Dialectical Social Science." Outlines. Critical Practice Studies 8 (2): $20-42$.

Lave, J., and E. Wenger. 1991. Situated Learning: Legitimate Peripheral Participation in Communities of Practice. New York: Cambridge University Press.

Light, R. 2006. "Situated Learning in an Australian Surf Club." Sport, Education and Society 11 (2): $155-172$.

Light, R. 2011. "Opening up Learning Theory to Social Theory in Research on Sport and Physical Education Through a Focus on Practice." Physical Education and Sport Pedagogy 16 (4): 369-382.

MacPhail, A., D. Kirk, and L. Griffin. 2008. "Throwing and Catching as Relational Skills in Game Play: Situated Learning in a Modified Game Unit." Journal of Teaching in Physical Education 27 (1): $100-115$.

Newman, F., and L. Holzman. 1993. Lev Vygotsky: Revolutionary Scientist. London: Routledge.

Quennerstedt, M. 2013. "Practical Epistemologies in Physical Education Practice." Sport, Education and Society 18 (3): 311-333. DOI:10.1080/13573322.2011.582245.

Quennerstedt, M., C. Annerstedt, D. Barker, I. Karlefors, H. Larsson, K. Redelius, and M. Öhman. In press. "What Did They Learn in School Today? A Method of Approach for Exploring Aspects of Learning in Physical Education." European Physical Education Review.

Quennerstedt, M., J. Öhman, and M. Öhman. 2011. "Investigating Learning in Physical Education A Transactional Approach." Sport, Education and Society 16 (2): 159-177.

Radford, L., and W. Roth. 2011. "Intercorporeality and Ethical Commitment: An Activity Perspective on Classroom Interaction." Educational Studies in Mathematics 77 (2-3): 227-245.

Roth, W., and Y. Lee. 2007. "Vygotsky's Neglected Legacy': Cultural-Historical Activity Theory." Review of Educational Research 77 (2): 186-232.

Roth, W., and L. Radford. 2010. "Re/Thinking the Zone of Proximal Development Symmetrically." Mind, Culture and Activity 17 (4): 299-307.

Rovegno, I., and J. P. Dolly. 2006. "Constructivist Perspectives on Learning." In The Handbook of Physical Education, edited by D. Kirk, D. Macdonald, and M. O'Sullivan, 242-261. London: Sage.

Samaras, A. P., and S. Gismondi. 1998. "Scaffolds in the Field: Vygotskian Interpretation in a Teacher Education Program." Teaching and Teacher Education 14 (7): 715-733.

Sfard, A. 1998. "On two metaphors for learning and the dangers of choosing just one." Educational Researcher 27 (2): 4-13.

Siedentop, D., P. Hastie, and H. van der Mars. 2011. Complete Guide to Sport Education. Champaign, IL: Human Kinetics.

Slavin, R. 1996. "Research on Cooperative Learning: What We Know and What We Need to Know." Contemporary Educational Psychology 21: 43-69. 
Tjeerdsma, B. L. 1998. "Cooperating Teacher Perceptions of and Experiences in the Student Teaching Practicum." Journal of Teaching in Physical Education 17 (2): 214-230.

Ussher, B., and C. Gibbs. 2002. "Vygotsky, Physical Education and Social Interaction." Journal of Physical Education New Zealand 35 (1): 76-86.

Vygotsky, L. 1978. Mind in Society: The Development of Higher Psychological Processes. Cambridge: Harvard University Press.

Wallhead, T., and M. O'sullivan. 2005. "Sport Education: Physical Education for the New Millennium?" Physical Education and Sport Pedagogy 10 (2): 181-210.

Ward, P., and M. Lee. 2005. "Peer-Assisted Learning in Physical Education: A Review of Theory and Research." Journal of Teaching in Physical Education 24 (3): 205-225.

Webb, N., and A. Mastergeorge. 2003. "Promoting Effective Helping in Peer-Directed Groups." International Journal of Educational Research 39 (1-2): 73-97. 